\title{
Die Lippen verrieten die Diagnose
}

\author{
Wegen Bluterbrechens wurde bei \\ einem 32-jährigen Patienten eine Gas- \\ troskopie durchgeführt. Dabei stellte \\ man multiple Teleangiektasien nicht \\ nur im Magen, sondern auch an den \\ Lippen und in der Mundschleimhaut \\ fest. Dieser Befund beweist die Diagno- \\ se einer hereditären Erkrankung.
}

- Der Patient wurde wegen einer akuten oberen gastrointestinalen Blutung mit Hämatemesis und Teerstuhl stationär aufgenommen. Bei der Aufnahme war er kreislaufmäßig stabil. Die Laboruntersuchung zeigte eine hypochrome mikrozytäre Eisenmangelanämie. Die übrigen Laborwerte lagen im Normbereich.

\section{Immer wieder Nasenbluten}

Bei genauem Befragen gab der Patient an, dass er seit vielen Jahren an einer rezidivierenden Epistaxis leide. Von HNO-ärztlicher Seite sei mehrmals eine Tamponade und eine „Verödung“ durchgeführt worden. Auch habe er in den vergangenen Jahren gelegentlich schwarzen Stuhl beobachtet, was jedoch nicht weiter abgeklärt wurde.

\section{Teleangiektasien im Magen}

Im Zuge der Gastroskopie fielen multiple Teleangiektasien im Bereich der Lippen und der Mundhöhle auf. Ein ähnlicher Befund zeigte sich in der Magenschleimhaut. Auch hier fanden sich multiple Gefäßerweiterungen mit Zeichen einer frischen Blutung. Angesichts dieses Befundes wurde die Diagnose Morbus Osler gestellt.

\section{Seltene Erbkrankheit}

Beim Morbus Osler-Weber-Rendu handelt es sich um eine autosomal-dominant vererbte Erkrankung, bei der es zu einer krankhaften Erweiterung von Blutgefäßen kommt. Deshalb spricht man auch von einer hereditären hämor-

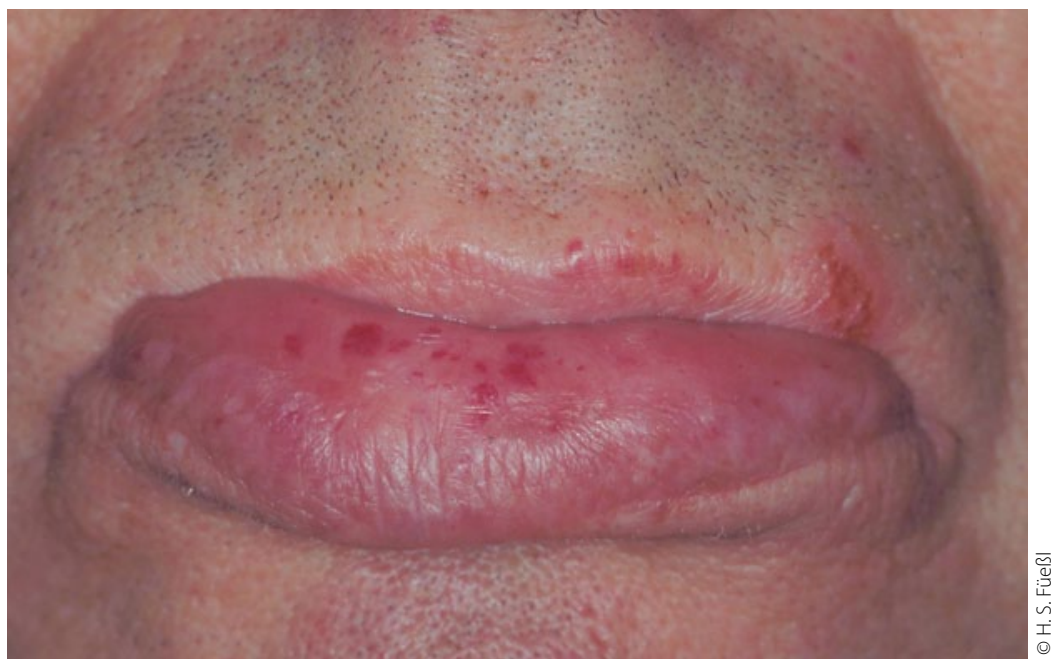

Zahlreiche Teleangiektasien an den Lippen.

rhagischen Teleangiektasie. Die Erkrankung ist selten, d.h. in Deutschland sind ca. 35000 Menschen betroffen. Es gibt verschiedene Mutationen, die zu einem Morbus Osler führen können. Zwei dieser Gene können heute analysiert werden.

\section{Viele Organe betroffen}

Die für die Erkrankung typischen Teleangiektasien können überall auftreten, vor allem in Nase, Mund, Gesicht und Schleimhäuten des Magen-DarmTraktes. Wegen der stark erhöhten Vulnerabilität der Gefäßerweiterung kommt es zu Einrissen mit konsekutiven Blutungen, vor allem in Form von Nasenbluten oder gastrointestinalen Blutungen. Die ersten Symptome der Erkrankung treten meist in der Pubertät auf, wobei Nasenbluten als Initialsymptom im Vordergrund steht. Die rezidivierenden Blutungsereignisse können $\mathrm{zu}$ einer Eisenmangelanämie führen.

In ca. $20-30 \%$ aller Fälle treten zusätzliche Gefäßerweiterungen in den Lungen auf, die als pulmonale arteriovenöse Malformationen bezeichnet werden. Diese Veränderungen können zu einem Links-Rechts-Shunt führen. Dies kann eine Überlastung der pulmonalen Strombahn und somit des rechten Herzens mit konsekutiver Rechtsherzinsuffizienz zur Folge haben. Aber auch in der Leber können solche Gefäßkurzschlüsse auftreten. In Einzelfällen wurden auch Schlaganfälle und Hirnabszesse beschrieben, wobei Gerinnsel bzw. Bakterien aus der venösen Strombahn über die pulmonalen Shunts in das Gehirn gelangen.

Eine kausale Therapie steht nicht zur Verfügung. Bei stärkeren Blutungen, vor allem im Magen-Darm-Trakt, ist eine endoskopische Intervention erforderlich.

Dr. med. Peter Stiefelhagen .

\section{Fabula docet}

Bei rezidivierenden Nasen- oder Magen-Darm-Blutungen sollte auch an eine seltene hereditäre Erkrankung, nämlich den Morbus Osler gedacht werden. Schon der Blick auf die Lippen zeigt die typischen Teleangiektasien. Zusammen mit der Familienanamnese ist damit die Diagnose gesichert. 